\title{
Experiences of persons with multiple chemical sensitivity with mental health providers
}

\author{
This article was published in the following Dove Press journal: \\ Journal of Multidisciplinary Healthcare \\ 6 April 2016 \\ Number of times this article has been viewed
}

\section{Pamela Reed Gibson \\ Sharon D Lockaby \\ Jenna Michele Bryant \\ Department of Psychology, James Madison University, Harrisonburg, VA, USA}

Correspondence: Pamela Reed Gibson Department of Psychology, James Madison University, MSC 7704,

Harrisonburg,VA 22807, USA

Tel + I 5405686195

Fax +I 5405683322

Email gibsonpr@jmu.edu
Abstract: In this paper, we summarize the results of an online survey of persons in the United States with chemical intolerance/multiple chemical sensitivity who sought help from mental health providers, including counselors, psychologists, psychiatrists, and others. Respondents reported on their most recent contact with a provider, describing reasons for the contact, accommodations requested and received, and suggestions for how the experience could be more helpful. Overall, though clients were accommodated in small ways, some received no accommodation, and many felt that the providers needed to be more knowledgeable regarding chemical intolerance. Results are discussed in terms of the importance of providers becoming more aware of multiple chemical sensitivity and more willing to make their services accessible to these clients.

Keywords: multiple chemical sensitivity, chemical sensitivity, chemical intolerance, emerging disability, contested illness

\section{Introduction}

Multiple chemical sensitivity (MCS), also known as chemical intolerance (CI) or chemical hypersensitivity, is an emerging disabling illness characterized by chronic adverse effects from exposure to low levels of chemicals in the modern human environment. It may or may not be accompanied by electrical hypersensitivity. Symptoms can range from mild to disabling and commonly include fatigue, nausea, dyspepsia, rhinitis, confusion, change in heart rate, irritability, dizziness, and headache. ${ }^{1}$ The most common chemicals described as causing reactions are pesticides, petrochemicals, household cleaners, exhausts, dry cleaning chemicals, perfumes, smoke, and air fresheners. ${ }^{1}$ Prevalence rates vary depending upon the wording of population surveys, but chemical sensitivity appears to be an international problem. In the US, Caress and Steinemann ${ }^{2}$ found that $12.6 \%$ of a household population study reported being unusually sensitive to common chemical substances. Meggs et $\mathrm{al}^{3}$ found that $33 \%$ of persons in a US household population survey reported some chemical sensitivity (CS), with $3.9 \%$ reporting becoming ill every day from exposures. Katerndahl et $\mathrm{al}^{4}$ found that $20 \%$ of 400 people in family medicine waiting rooms met the criteria for CI.

In the Netherlands, $27 \%$ reported multiple symptoms from chemicals, ${ }^{5}$ while in

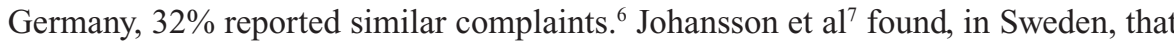
$32 \%$ reported some odor intolerance, with 19\% having some life impacts from the intolerance. In the same country, $15.6 \%$ of teenagers reported CS. ${ }^{8}$ And in Korea, the prevalence is estimated at $16.4 \%$, with higher numbers among people with atopic dermatitis and those who have lived in new housing. ${ }^{9}$ Thus, sensitivity/intolerance to 
chemicals is reported to occur in multiple countries. Though found internationally, and crossing the lines of race, income, and age, ${ }^{10} \mathrm{MCS}$ does seem to disproportionately affect women. ${ }^{5,8,11}$ The Japanese researchers Imai et al ${ }^{12,13}$ have made pleas for health professionals to attend to indoor air quality and to learn to counsel those with sensitivities as to how to avoid chemical exposure in their daily lives.

Researchers have, to date, only discussed MCS in the industrialized countries of Japan, Korea, Sweden, Germany, Canada, USA, Spain, France, and the Netherlands. Grassroots groups have advocated for recognition in Australia. The prevalence of CS in indigenous areas is uncertain. It may exist primarily as a result of living in highly artificial environments. However, Johnson ${ }^{14}$ has described in detail the sensitivity-related illness experienced by persons exposed to the September 11, 2001, World Trade Center bombing in New York, the Katrina aftermath in New Orleans, and the clean-up following the oil spill by the Exxon-Valdez in Alaska, USA. It is certain that indigenous persons experience heavy chemical exposures such as these as a result of industrial sitings, chemical spills, and lesser environmental standards for industrial ventures. For example, in Ecuador, indigenous groups have sued Chevron-Texaco for extreme contamination of their forest home, ${ }^{15}$ a long-running case only recently resulted in an Ecuadorean appeals court upholding a ruling against Chevron and requiring the company to pay 18.2 billion dollars in damages. ${ }^{16,17}$ It is well known that Nigeria is heavily contaminated as a result of oil extraction $^{18}$ and that toxic pesticides no longer legal in the US are exported for use in less developed countries.

Though some progress has been made in understanding sensitivities in industrialized countries, persons with these "contested" and emerging illnesses still have difficulties in obtaining help with the challenges of living with poorly understood conditions. Persons with MCS seek psychological help for a variety of reasons. Some are referred to psychologists when medical providers fail to find obvious bodily damage and assume that the problem is psychosomatic. Others go for help with any concomitant mental health issues or are unaware that they have reactions to chemicals. Additionally, in the USA some persons are required to have a psychological evaluation when applying for social security disability income.

The field of sociology preceded psychology in examining and understanding chronic illness. ${ }^{19,20}$ Charmaz $^{21}$ has described the alienation from the body and the changes in identity goals that accompanied surrendering to chronic illness in 55 adults with chronic illness. Though psychology has been slower to recognize the needs of those with chronic illness, writers within this field have focused on the support needs and ways of responding to individuals with chronic illness and their families. ${ }^{22,23}$ Kennedy et $\mathrm{al}^{24}$ admitted in 2001 that the psychological professions were just beginning to address the chronically ill.

More specifically, psychological researchers have discussed coping from an empathic perspective for noncontested conditions, such as renal failure, ${ }^{25-27}$ rheumatoid arthritis, ${ }^{28}$ multiple sclerosis, ${ }^{26}$ and others. ${ }^{29}$ Over time, the findings of these studies are becoming integrated into health care provision to the benefit of patients.

However, contested illnesses take longer to integrate into the health literature. MCS, in particular, has been the subject of heated debate regarding etiology, with some exploring psychogenic pathways. Though a thorough summary of etiology research is beyond the scope or space of this paper, research on causation has been fairly polarized. Skovbjerg et $\mathrm{al}^{30}$ found neuroticism to be a small predictor of CI and cite this as support for the role of negative effect in the development of CI. Bailer et $\mathrm{al}^{31}$ examined trauma in persons with "idiopathic environmental intolerance" (IEI), somatoform, disorder, and in controls. No differences were found regarding general or sexual trauma, but those with IEI and somatoform cited more exposure to unspecified and "life-threatening illness". The authors believe that "These life events may foster the development of dysfunctional beliefs, direct attention toward bodily symptoms of potential illnesses, and lead to enhanced symptom reports". In a later study, Bailer et al ${ }^{32}$ used the Modern Health Worries Scale that examines concerns about radiation, environmental pollution, tainted food, and toxic interventions. Persons with IEI [sic] had higher worries than controls, leading the authors to attribute chemical sensitivities to an attributional style. (But the relationship between the worries measured and the participants' health condition calls this interpretation into question due to circular reasoning).

Researchers who view the condition as physiological have found a strong overlap with allergy and asthma, ${ }^{10,11}$ vitamin and mineral deficiencies, ${ }^{33}$ enzymatic deficiencies and genetic alleles, ${ }^{34}$ immunological factors, ${ }^{35}$ including proinflammatory indicators, ${ }^{36}$ genetic variations, ${ }^{34}$ and mixed results regarding upper airway inflammation. ${ }^{37,38}$ The "olfactory kindling hypothesis" has found some support ${ }^{39}$ with evidence from animal studies. ${ }^{40,41}$ There is some suggestion of elevated histamine both during and between exposures ${ }^{42,43}$ and some positive correlation between real-time volatile organic compound exposures as measured by canisters and reports of symptoms $^{44,45}$ and serious neurological changes (decrease 
in brain perfusion) on single-photon emission computed tomography scans in a number of cortical areas during chemical exposure for persons with MCS when compared with controls. ${ }^{46}$ Orriols et $\mathrm{al}^{46}$ also found changes in brain function before and after exposure in the MCS group and say that their findings "suggest a neurologic pathogenesis of this disorder". Belpomme et $\mathrm{al}^{42}$ reported opening of the blood-brain barrier and decreased blood flow in the temporal lobes as well.

Andersson et $\mathrm{al}^{8}$ found that anxiety, but not depression, correlated with CS and speculated that depression may develop as a result of the sensitivity. The relation with anxiety was only correlational, and Bloch and Meggs ${ }^{11}$ found that anxiety was related to allergy and asthma as well as CS. Similarly, Bloch and Meggs ${ }^{11}$ found that panic also has a nonunique relationship with MCS, suggesting "that chemical sensitivity is a member of a larger family of diseases that have a common relationship with anxiety and panic". Gundersen et $\mathrm{al}^{47}$ found no relationship between MCS and anxiety or depression. In an older study, Bertschler et $\mathrm{al}^{48}$ found that mental health indicators improved following treatment for chemical sensitivities, suggesting that psychological discomfort is secondary to the illness. Heuser et $\mathrm{al}^{49}$ suggested in 1992, after finding considerable evidence of neurological abnormality, that the "psychiatric presentation by many of these patients may well have a neurological basis."

Though practitioners who do not believe that MCS is of physiological origin suggest that patients expose themselves gradually to chemicals, Fox and Sampalli ${ }^{50}$ found evidence in an exposure booth study that those with MCS did not accommodate to a series of three exposures to dryer sheets, but continued to manifest changes in "skin temperature and conductance, respiratory and heart rate, and surface electromyography (EMG)".

Cui et al $^{51}$ argue for an integrative "multifactorial psychobiological" process model rather than one that is unidirectionally psychogenic or physiological. The authors found that MCS in Japanese factory workers did predict mental health issues on the Quick Environmental Exposure and Sensitivity Inventory (QEESI), though their study model constructed mental health effects as secondary to MCS. Dantoft et al ${ }^{52}$ have created an integrative summary of the etiological research on MCS and call for researchers to set aside the dichotomy and pursue interdisciplinary work in order to positively impact those who experience the illness.

Dumit $^{53}$ has referred to conditions such as fibromyalgia, chronic fatigue syndrome, and MCS as "Illnesses you have to fight to get", in that without a clear medical label, these persons lack the medical validation that confers legitimacy. Thus, invisible/emerging/marginalized/contested conditions leave persons with the task of struggling for validation and access to resources. Fox and $\mathrm{Kim}^{54}$ observed that "The barriers faced by individuals from emerging disability groups often prevent experiencing the benefits of participation in society".

The life impacts of having CS/CI may include joblessness, lack of medical care, lack of community access, ${ }^{55}$ social isolation, and even homelessness. ${ }^{1}$ Workplace harassment is not uncommon, and may possibly, along with lack of job accommodations, be a factor in joblessness. ${ }^{56}$ Not surprisingly, persons with these struggles report personal distress. When the symptoms become severe, persons often apply for disability benefits as a result of the inability to continue in the workplace..$^{57,58}$

Despite the use of mental health providers as gatekeepers in the acquisition of disability support, they appear to be generally unprepared to work with this problem. And given the history of women's health care ${ }^{59-61}$ and the sex biases in psychological care, ${ }^{62,63}$ it is not surprising that persons with CI would report some difficulty in accessing support in the psychological community. Gibson et $\mathrm{al}^{1}$ found that 187 of 268 persons with self-reported MCS had seen a total of 549 mental health providers. Only $17 \%$ of these providers were seen as being informed regarding MCS and 36\% were perceived as helpful. Respondents reported that their CS was ignored $(n=119)$, that they received psychogenic labels $(n=102)$ and psychoactive medications $(n=83)$, and that providers suggested $(n=33)$ or implemented $(n=28)$ psychiatric hospitalization. More recently, Doiron ${ }^{64}$ found that even providers who had been working with this population for some time showed little understanding of clients' difficulties or needs. Likewise, in Japan, Imai et al" found that "lack of knowledge about the disorder" and "difficulty in establishing a diagnosis" comprised two of the three major obstacles that aggravate symptoms of sick house syndrome or CS.

Similar experiences may be encountered when persons with MCS attempt to access services at Centers for Independent Living. Gibson et $\mathrm{al}^{65}$ found that services received by consumers with MCS were uneven and unpredictable and that, although some persons received helpful services, advocates turned others away and were unfamiliar with MCS or the needs of those who experience it.

In this article, we summarize the experiences of a sample of persons in the US with MCS who sought help from psychological providers for various reasons. We discuss the experiences of persons with sensitivities who visited 
psychological providers and their views regarding ways to improve services for this population. To our knowledge, this is the first study of the experiences of persons with CI with psychological providers.

\section{Methods}

\section{Participants}

The respondents were 46 women and 14 men from the US. Fifty-five (91.7\%) participants were physician diagnosed with MCS, four (6.7\%) were self-diagnosed, and one did not answer this question. The results may not be representative of patient experiences in other countries.

\section{Materials}

The 45 -question survey contained demographic questions regarding age, sex, and household income, as well as questions regarding how many and what types of mental health providers they had seen and for what reasons. We then asked the responders to concentrate on one specific experience with their most recent mental health provider and to answer questions about that contact in terms of accommodations asked for and received, the reason for the contact, and how the experience could have been better.

We also used the Satisfaction with Life Scale (SWLS) comprising five questions on a 7-point Likert-type scale (total scores can range from 5 to 35). ${ }^{66}$ The questions are broad and not anchored to specific life realms, as Diener ${ }^{67}$ believes that respondents should be free to anchor life satisfaction on their own criteria. The measure has shown satisfactory internal consistency $(r=0.87)^{68}$ and test-retest reliability $(r=0.82){ }^{66}$ The scale is not correlated with social desirability, sex, age, or educational level. ${ }^{68}$

\section{Procedure}

The 44-question survey was developed on Qualtrics, an online survey maker. After receiving study approval from the James Madison University Institutional Review Board, the link to the survey was placed on our MCS research website for $\sim 5$ months (www.mcsresearch.net). We also informed multiple support and advocacy groups that we were conducting the study and asked for their help in distributing our call to the participants. Paper copies were offered for those who could not access the survey online. When accessing the link to the study, respondents first viewed an informed consent document and were advised that pushing the "next" button after reading the consent implied agreement to participate; responses were thus anonymous. Persons could discontinue participation at any point. Demographic and other closed-ended questions were analyzed using the SPSS package. Open-ended questions were read and tallied for content. We did content analysis, created categories, and resolved any disagreements through discussion.

\section{Results}

Sixty persons returned usable complete surveys, 57 of which were Caucasian (three classified themselves as "other"). Forty-six participants were female. Fifty-four considered themselves to be disabled and four did not (two did not answer). There was a range of educational levels: one person had completed some high school, ten had high school degrees, nine had associate's degrees, 12 had technical degrees, 16 had bachelor's degree, ten had master's degrees, and two had doctoral degrees. Marital status varied: 14 participants being single, 22 married, 19 divorced, and five living with partners. Over two-thirds (66.7\%) were not employed, ten $(16.7 \%)$ worked from home, three $(5.0 \%)$ worked parttime, and seven (11.7\%) worked full-time. Most respondents (55) had lost or had been forced to quit a job because of their sensitivities. The mean age of participants was 52.4 with a range of 30-77. Mean household income was $\$ 35,845$ and ranged from 0 to $\$ 145,000$. Personal income ranged from 0 to $\$ 90,000$ with a mean of $\$ 19,657$. Respondents had been aware of their disorder for a mean of 14 years and had seen a mean of 4.5 mental health providers, with 20 being the highest number seen. Participants rated their level of disability as mild $(10 \%)$, moderate $(19.0 \%)$, severe $(46.6 \%)$, or totally disabled (24.1\%).

People sought providers' help for a variety of reasons. As we expected, there were people who were forced to seek services as part of the social security or private disability compensation application. Others were looking for stress management, medication reviews, or validation that their condition was physiological. Most participants were seeking counseling of some sort. People commonly sought counseling for a variety of reasons, including work or social discrimination, difficulty in physical functioning, and other issues related to MCS. Many were grieving over their loss of access (ie, their inability to have contact with much of the world because of their intolerances). Some respondents needed medication reviews because they were taking medications for unrelated health conditions. When asked what type of mental health providers they had seen, $40(66.7 \%)$ reported visiting psychiatrists, 42 (70\%) had seen psychologists, $25(41.7 \%)$ had seen counselors, $13(21.7 \%)$ had visited social workers, and eleven (18.3\%) had accessed other mental health providers such as neuropsychologists or neurologists (some 
saw more than one type of provider). Some respondents listed priests and nurses as their mental health providers. Most persons sought counseling/coping help or evaluation for disability. Table 1 lists the services sought by all 60 respondents. (The tables are not meant to be summative, as not all participants requested accommodations, not all accommodations requested were given, and some participants requested more than one accommodation).

Respondents requested and received varying levels of accommodation for their visits. The most commonly requested accommodations included a fragrance-free environment, being seen in a different location, a chemical-free room, being able to avoid the waiting room, and others as listed in Table 2. Some mental health providers were quite accommodating in that they were willing to forego the use of scent for a day or meet outside of their offices. Although providers made a variety of accommodations for their clients, some could not control access to their entire buildings. For example, one participant said, "The office has signage up that it is a chemical free environment and staff do not wear fragranced products, however, main entry and elevator to the office in the building is [sic] often full of chemical smells". While visiting providers, 45 participants $(75 \%)$ had asked for special accommodations for their sensitivities and 30 people $(50 \%)$ said they had been met. Many respondents felt there was more their providers could have done regarding accommodations.

When asked to evaluate their provider's knowledge of MCS on a scale of "not knowledgeable", "somewhat knowledgeable", or "highly knowledgeable", 25 (41.7\%) said their provider was "not knowledgeable", 27 (45\%) said "somewhat knowledgeable", and only seven (11.7\%) said "highly knowledgeable". When rating the experience of the provider

Table I Services sought from mental health providers by 60 persons with MCS

\begin{tabular}{lc}
\hline Services & $\mathbf{n}$ \\
\hline Counseling/help with coping & 21 \\
Disability evaluation & 13 \\
Help with depression & 7 \\
Medication review & 5 \\
Validation that condition is physical & 2 \\
Workers compensation evaluation & 2 \\
Help understanding neurological symptoms & 2 \\
Evaluation (referred by the primary care provider) & $\mathrm{I}$ \\
Help sorting out chemical reactions from depression & $\mathrm{I}$ \\
Required evaluation for Center for Independent Living & $\mathrm{I}$ \\
Help dealing with loss & $\mathrm{I}$ \\
Help for problems with getting sick at work & $\mathrm{I}$ \\
\hline
\end{tabular}

Abbreviation: MCS, multiple chemical sensitivity.
Table 2 Accommodations made by mental health providers for 60 persons with MCS

\begin{tabular}{ll}
\hline Accommodations & $\mathbf{n}$ \\
\hline No fragrance & 9 \\
Seen in a different location (including outside or different room) & 9 \\
Chemical-free room & 5 \\
Allowed to avoid the waiting room & 4 \\
Allowed to wear a mask & 4 \\
Opened the window & 3 \\
Turned off fluorescent lights and/or electric equipment & 3 \\
No air freshener & 2 \\
Telephone therapy & 2 \\
Answered orally instead of writing & I \\
Warned of fresh paint & I \\
Allowed breaks to cope with fatigue & I \\
Special chair & I \\
Closed the door & I \\
No keyboard typing & I \\
Seen as first client of the day & I \\
Practitioner tried to have a room scent-free (but remnants lingered) & I \\
\hline
\end{tabular}

Abbreviation: MCS, multiple chemical sensitivity.

regarding MCS, 39 persons (65\%) said "not experienced", $17(28.3 \%)$ stated "somewhat experienced", and only four (6.7\%) said "highly experienced". The most common complaint was that the provider was not experienced regarding MCS. Thirty-eight percent of participants had received refusals for help from mental health providers in the past because of a lack of knowledge or an inability/unwillingness to accommodate the respondents.

When describing how the experience could have been better, respondents named variables related to both the setting and practitioner behavior. Persons wanted a safer physical environment in which to be seen that was smoke- and scentfree, with windows that opened. They wanted to avoid waiting rooms and new construction and to be seen in their own homes. Many respondents mentioned wanting knowledgeable providers who would believe them and recognize MCS as a physical condition, and offer understanding, compassion, and support for their condition and its associated lifestyle changes (Table 3).

When asked about the worst aspect of their experience with mental health providers, respondents listed variables that fell into three categories: the exposures that occurred as a result of the interaction, the tendency to see MCS as psychogenic, and the lack of responsiveness on the part of the providers. Exposure problems included fragrance on furniture and on people, having to wear a mask to attempt to avoid such exposures, and becoming sick from the experience. The tendency of the provider to construct MCS as psychogenic caused some clients to receive psychological 
Table 3 How could mental health provision have been better according to 60 persons with MCS

\begin{tabular}{ll}
\hline How could help have been better? & $\mathbf{n}$ \\
\hline Provider should have been more educated & I0 \\
The experience was already positive & 7 \\
Provider could have "believed" me & 3 \\
Discussion of and help with lifestyle changes & 3 \\
Provider recognize MCS as a physical condition & 2 \\
Safer office & 2 \\
An in-home intervention to set up family support & 2 \\
Providers should not push antidepressants & $\mathrm{I}$ \\
Have an advocate at each hospital & $\mathrm{I}$ \\
Be able to avoid waiting rooms & $\mathrm{I}$ \\
Windows that open & $\mathrm{I}$ \\
No smoking & $\mathrm{I}$ \\
Do not make us fight for the accommodations & $\mathrm{I}$ \\
A scent-free environment & $\mathrm{I}$ \\
Having a closer provider & $\mathrm{I}$ \\
In-person counseling & $\mathrm{I}$ \\
Break up testing over several days & $\mathrm{I}$ \\
Not going at all & $\mathrm{I}$ \\
Referral to Medicare/Medicaid provider & $\mathrm{I}$ \\
Understanding/compassion & $\mathrm{I}$ \\
I could have been accepted for full disability & $\mathrm{I}$ \\
I should have found someone more qualified & $\mathrm{I}$ \\
\hline
\end{tabular}

Abbreviation: MCS, multiple chemical sensitivity.

labels and be given psychogenic medications. One client was required to take the Minnesota Multiplasic Personality Inventory, a test usually reserved for clients assumed to have some mental pathology. Respondents mentioned being tested only for psychological problems and not for toxic brain syndromes, being seen as trying to get out of working, and having to be on guard so as not to be perceived as having a psychological disorder. The embarrassment of discussing a condition that could be perceived as psychological was also mentioned as the worst aspect of visiting a mental health provider. Behaviors from providers that demonstrated a lack of responsiveness on the part of the provider included getting no accommodations, perceiving that the provider had no understanding of MCS, having symptoms dismissed, feeling humiliated, and "feeling as if I were talking to a stump". All responses are listed in Table 4.

\section{Satisfaction with Life Scale}

Scores on the SWLS were generally low, with a mean of 12.2 of a possible 35 , a very low score even for persons with chronic medical issues.

\section{Discussion}

Although some participants were satisfied with their interactions with mental health providers, many felt that
Table 4 Worst aspect of seeing mental health providers for 60 persons with MCS

\begin{tabular}{ll}
\hline Aspect & $\mathbf{n}$ \\
\hline Getting a psychological label & 5 \\
Getting no accommodations & 4 \\
Provider not understanding MCS & 3 \\
Not being believed regarding symptoms & 3 \\
Exposures in the setting & 3 \\
Having to go through a stinky building to get there & 2 \\
Being given psychiatric medication & 2 \\
There was no worst aspect & 2 \\
Getting no help & 2 \\
Being humiliated/demeaned & 2 \\
Talking through a mask & $\mathrm{I}$ \\
Taking the MMPI & $\mathrm{I}$ \\
Getting sick & $\mathrm{I}$ \\
The exhaustion & $\mathrm{I}$ \\
Fragrance on chairs & $\mathrm{I}$ \\
Fragrance on employees & $\mathrm{I}$ \\
The cost & $\mathrm{I}$ \\
Lost disability benefits & $\mathrm{I}$ \\
Being on guard so as not to be perceived as psychiatric & $\mathrm{I}$ \\
No testing for toxic encephalopathy only for psychological disorders & $\mathrm{I}$ \\
Being seen as trying to get out of work & $\mathrm{I}$ \\
Admitting it is chronic/lifelong & $\mathrm{I}$ \\
Embarrassment of talking about a disorder that could be perceived & $\mathrm{I}$ \\
as psychiatric & \\
Admitting that it could be a brain defect "on record" & $\mathrm{I}$ \\
Having an aloof examiner document notes & $\mathrm{I}$ \\
Lack of support/advice/discussion & $\mathrm{I}$ \\
Feeling as if I were talking to a stump & $\mathrm{I}$ \\
\hline Getting depressed and upset & \\
\hline
\end{tabular}

Abbreviations: MCS, multiple chemical sensitivity; MMPI, Minnesota Multiplasic Personality Inventory.

there was much room for improvement, and we gathered valuable data for designing a training module for mental health providers who work with persons with MCS (to be presented elsewhere). We found that more than half of the providers seen were not considered knowledgeable about MCS. Egeli et $\mathrm{al}^{69}$ found that patients with fibromyalgia (another contested illness) were more satisfied when their physicians were knowledgeable and supportive and listened to their concerns. Many of the recommendations suggested by Egeli et al's participants for their physicians resembled those of ours regarding their mental health providers. Our participants were looking for providers with more knowledge of MCS and alternative treatment methods and were expecting the provider to learn with them and to take extra time to adequately discuss treatments. In our study, over $83.3 \%$ of participants considered their mental health provider only somewhat or not experienced. Only $6.7 \%$ believed their provider to be highly experienced regarding this health condition. Many wished that the providers had been willing 
to research the subject before their session so they would have a better understanding of the client's dilemma. Yet, many felt that their visit was positive overall.

Disability benefits from the government would ease the struggles with money and payments to medical centers for MCS clients. A number of respondents reported very negative experiences in having to undergo psychological assessment in order to acquire the needed disability benefits. One of the major themes that the current study has highlighted is that the clients do not see themselves as mentally ill but as disabled by their experiences with MCS. Some of their experiences with providers were helpful because they were able to secure help for their problems resulting from the MCS. Some contacts eventually resulted in acquiring disability benefits. Yet, some acquired psychological labels that will persist on their health records. Gibson ${ }^{70}$ reported that some persons, out of financial desperation, felt forced to accept psychological diagnoses though they believed them to be incorrect. Others were not even aware of the diagnosis used to grant them benefits. The danger in misinterpreting women's health conditions as psychogenic was addressed by Klonoff and Landrine, ${ }^{71}$ who reviewed health conditions that tend to manifest either more often or solely in women (eg, multiple sclerosis, hypothyroidism, temporal lobe epilepsy). The authors believe that the psychological "overlay" or mimic of psychological symptoms in many physical illnesses may account for the preponderance of women receiving depression and anxiety diagnoses from both primary care and psychological providers. For example, hypothyroidism may present with depressive symptoms. Yet Klonoff and Landrine state that the use of antidepressants can worsen the condition and even be fatal. Women with MCS may face the same risks, as antidepressants were rated as more harmful than helpful by a large sample of persons when used as a treatment for CI. ${ }^{72}$

Life satisfaction scores were lower than even previously found for persons with MCS. Gibson et $\mathrm{al}^{73}$ found a mean SWLS score of 14.86, (standard deviation $(\mathrm{SD})=7.64$ ) in 209 persons with MCS. This is the second study to find low life satisfaction in persons with MCS compared with other published samples. Previous researchers found that medical outpatients and elderly patients scored means of 23.5 and 25.8 , respectively, on the SWLS. ${ }^{66,68,74}$ In the Gibson et $\mathrm{al}^{73}$ study, lower life satisfaction was significantly correlated with the course of illness (having gotten worse), being fatigued, having low leisure satisfaction, having a lower income, and having no romantic relationship.

Many participants in the current study had lost spouses, jobs, and the freedom to leave their own houses. These cumulative losses are consistent with findings from other studies; these losses and the lack of access may explain the low mean SWLS scores. This underscores the need for counseling and support regarding coping with chemical and electrical intolerance. ${ }^{13}$ There is a great need for more research on the physical causes of MCS, effective interventions, and the support of this population by mental health providers. The importance of according legitimacy to clients' complaints cannot be overestimated. Our results are consistent with those of Bernard et al, ${ }^{75}$ who found that 270 participants with fibromyalgia reported in open-ended questions that they wanted their health care professionals to be more educated about their particular disease and to offer better services to help manage their disease. Similarly, Lehman et $\mathrm{al}^{76}$ found when studying respondents with chronic fatigue syndrome, that the most popular response $(36 \%)$ to the question "what is the most unhelpful or upsetting thing that a medical professional has said or done to you", was failure to legitimize the patient's experience of illness. Interestingly, the most popular response $(52 \%)$ to the query "what is the most helpful thing that a medical professional has said or done to you" was legitimizing the illness, either through diagnosis or by acknowledging the presence of symptoms. Respondents in the Lehman et al study, who reported not feeling legitimized by their physicians, also demonstrated significantly higher depression and anxiety scores than those who felt legitimized.

When MCS and other emerging disabilities gain legitimacy, people will be able to seek effective services. Though disagreement regarding etiology persists, researchers are beginning to hypothesize and uncover neurological effects of chemical exposure in persons with CI. Medical acceptance and understanding of this condition, proper financial benefits, and work accommodations would go a long way toward improving the quality of life for persons with environmental intolerances. We believe it is the responsibility of health care providers to study emerging illnesses and disabilities and to contribute positively to the care of those who experience them. Koch et al would like rehabilitation counselors to challenge their own biases toward MCS, revise their understanding of universal design, accommodations, and accessibility, and learn to help clients to communicate with their work supervisors and erode their psychosocial isolation. ${ }^{77}$ Recently, Gibson et $\mathrm{al}^{78}$ found, in a grounded theory study, that the core activity of participants, "Healthquest", was literally a euphemism for "Resisting Annihilation", given the tremendous obstacles to seeking medical treatment for persons with MCS. In this study, 
respondents reported wanting their counselors to understand in detail the triggers, symptoms, and lifestyle requirements of those with MCS, to learn some toxicology, to understand how some psychological conditions such as depression and anxiety can be either toxin-induced or secondary reactions to the lifestyle restrictions, to apply the principles of doing good therapy to this population of disabled people, and to make it a priority to provide an accessible office. Until and unless therapists are able to address these needs, persons with MCS will struggle for even a modicum of help from the "helping" professions.

Limitations of this study include the nonrandom method of gathering volunteers and the fact that the participants were self-reported to have MCS.

\section{Acknowledgment}

Portions of this article were presented at the Southwest Conference on Disability, September 30-October 2, 2009, Albuquerque, New Mexico.

\section{Disclosure}

The authors report no conflicts of interest in this work.

\section{References}

1. Gibson PR, Cheavens J, Warren ML. Multiple chemical sensitivity/environmental illness and life disruption. Women Therapy. 1996;19:63-79.

2. Caress S, Steinemann AC. A review of a two-phase population study of multiple chemical sensitivities. Environ Health Perspect. 2003;111(12):1490-1497.

3. Meggs WJ, Dunn KA, Bloch RM, Goodman PE, Davidoff AL. Prevalence and nature of allergy and chemical sensitivity in a general population. Arch Environ Health. 1996;51(4):275-282.

4. Katerndahl DA, Bell IR, Palmer RF, Miller CS. Chemical intolerance in primary care settings: prevalence, comorbidity, and outcomes. Ann Fam Med. 2012;10(4):357-365.

5. Berg ND, Linnegarg A, Dirksen A, Elberling J. Prevalence of selfreported symptoms and consequences related to inhalation of airborne chemicals in a Danish general population. Int Arch Occup Environ Health. 2008;81(7):881-887.

6. Hausteiner C, Bornschein S, Hansen J, Zilker T, Förstl H. Self-reported chemical sensitivity in Germany: a population-based survey. Int $J$ Hyg Environ Health. 2005;208(4):271-278.

7. Johansson A, Brämerson A, Millqvist E, Nordin S, Bende M. Prevalence and risk factors for self-reported odour intolerance: the Skövde population-based study. Int Arch Occup Environ Health. 2005;78(7):559-564.

8. Andersson L, Johansson A, Millqvist E, Nordin S, Bende M. Prevalence and risk factors for chemical sensitivity and sensory hyperreactivity in teenagers. Int J Hyg Environ Health. 2008;211(5-6):690-697.

9. Jeong I, Kim I, Park HJ, Roh J, Park JW, Lee JH. Allergic diseases and multiple chemical sensitivity in Korean adults. Allergy Asthma Immunol Res. 2014;6(5):409-414.

10. Caress S, Steinemann A. Asthma and chemical hypersensitivity: prevalence, etiology, and age of onset. Toxicol Ind Health. 2009;25(1): 71-78.

11. Bloch RM, Meggs WJ. Comorbidity patterns of self-reported chemical sensitivity, allergy, and other medical illnesses with anxiety and depression. J Nutr Environ Med. 2007;16(2):136-148.
12. Imai N, Imai Y, Kido Y. Psychosocial factors that aggravate the symptoms of sick house syndrome in Japan. Nurs Health Sci. 2008;10(2):101-109.

13. Imai N, Imai Y. Necessity of counseling institutions for sick building syndrome. In: Abdul-Wahab SA, editor. Sick Building Syndrome in Public Buildings and Workplaces. Berlin: Springer-Verlag; 2011: 261-267.

14. Johnson A. Amputated Lives: Coping with Chemical Sensitivity. Brunswick, ME: Cumberland Press; 2008.

15. Walker $\mathrm{C}$, (director and producer), Avirgan, $\mathrm{T}$, (producer). Trinkets and Beads [videorecording]. A Cinemax Reel Life presentation; a Phantom/ Sunnyside/Faction Films production in association with Television Trust for the Environment. New York: Faction Films. First Run/Icarus Films (distributor); 1996.

16. Graydon N. Jungle Law. The Ecologist. Oct 2007; 33-40.

17. BBC News [webpage on the Internet]. Ecuador Appeals Court Rules Against Chevron in Oil Case. Available from: http://www.bbc.co.uk/ news/mobile/world-latin-america-16404268. Accessed January 5, 2012.

18. Pellow DN. Resisting Global Toxics: Transnational Movements for Environmental Justice. Cambridge, MA: MIT Press; 2007.

19. Charmaz K. Loss of self: a fundamental form of suffering in the chronically ill. Sociol Health Illn. 1983;5(2):168-195.

20. Strauss AL. Chronic Illness and the Quality of Life. St. Louis, MO: C. V. Mosby Company; 1984.

21. Charmaz K. The body, identity, and self: adapting to impairment. Sociol Q. 1995;36(4):657-680.

22. Altschuler J. Working with Chronic Illness. Hamshire: MacMillan; 1997.

23. Goodheart CD, Lansing MH. Treating People with Chronic Disease: A Psychological Guide. Washington, DC: American Psychological Association; 1997.

24. Kennedy P, Hopwood M, Duff J. Psychological management of chronic illness and disability. In: Milgrom J, Burrows GD, editors. Psychology and Psychiatry: Integrating Medical Practice. Chichester, NY: John Wiley and Sons, Ltd; 2001:183-211.

25. Hatchett L, Friend R, Symister P, Wadhwa, N. Interpersonal expectations, social support, and adjustment to chronic illness: personality processes and individual differences. [Electronic Journal]. J Pers Soc Psychol. 1997;73(3):560-573.

26. Singer MA, Hopman WM, MacKenzie TA. Physical functioning and mental health in patients with chronic medical conditions. Qual Life Res. 1999;8(8):687-691.

27. Symister P, Friend R. The influence of social support and problematic support of optimism and depression in chronic illness: a prospective study evaluating self-esteem as a mediator. [Electronic Version]. Health Psychol. 2003;22(2):123-129.

28. Schiaffino KM, Revenson TA. Why me? The persistence of negative appraisal over the course of illness. J Appl Soc Psychol. 1995;25(7):601-618.

29. Gatchel RJ. Coping with chronic or terminal illness. In: Gatchel RJ, Oordt MS, editors. Clinical Health Psychology and Primary Care. Washington, DC: American Psychological Association; 2003:213-233.

30. Skovbjerg S, Christensen KB, Ebstrup JF, Linneberg A, Zachariae R, Elberling J. Negative affect is associated with development and persistence of chemical intolerance: a prospective population-based study. J Psychosom Res. 2015;78(5):509-514.

31. Bailer J, Witthöft M, Bayerl C, Rist F. Trauma experience in individuals with idiopathic environmental intolerance and individuals with somatoform disorders. J Psychosom Res. 2007;63(6):657-661.

32. Bailer J, Witthoft M, Rist F. Modern healtah worries and idiopathic envioronmental intolerance. J Psychosom Res. 2008;65:425-433.

33. Galland L. Biochemical abnormalities in patients with multiple chemical sensitivities. Occup Med. 1987;2(4):713-720.

34. McKeown-Eyssen B, Baines C, Cole CEC, et al. Case-control study of genotypes in multiple chemical sensitivity: CYP2D6, NAT1, NAT2, PON1, PON2, and MTHFR. Int J Epidemiol. 2004;33(5):971-978. 
35. Meggs W. Immunological mechanisms of disease and the multiple chemical sensitivity syndrome. Multiple Chemical Sensitivities: Addendum to Biologic Markers in Immunotoxicology. Washington, DC: National Research Council, National Academy Press; 1992:155-168.

36. Dantoft TM, Elberling J, Brix S, Szecsi PB, Vesterhauge S, Skovbjerg $\mathrm{S}$. An elevated pro-inflammatory cytokine profile in multiple chemical sensitivity. Psychoneuroendocrinology. 2014;40:140-150.

37. Meggs WJ. Multiple chemical sensitivities: chemical sensitivity as a symptom of airway inflammation. J Toxicol Clin Toxicol. 1995; 33(2):107-110.

38. Dantoft TM, Skovbjerg S, Andersson L, et al. Inflammatory mediator profiling of n-butanol exposed upper airways in individuals with multiple chemical sensitivity. PLoS One. 2015;10(11):e0143534. doi: 10.1371/ journal.pone.0143534.

39. Bell IR, Miller CS, Schwartz GE. An olfactory-limbic model of multiple chemical sensitivity syndrome: possible relationship to kindling and affective spectrum disorders. Biol Psychiatry. 2002;32:218-242.

40. Rossi J. Sensitization induced by kindling and kindling-related phenomena as a model for multiple chemical sensitivity. Toxicology. 1996;111:87-100.

41. Rogers WR, Miller CS, Bunegin L. A rat model of neurobehavioral sensitization to toluene. Toxicol Ind Health 1999;15:356-369.

42. Belpomme D, Campagnac C, Irigaray P. Reliable disease biomarkers characterizing and identifying electrohypersensitivity and multiple chemical sensitivity as two etiopathogenic aspects of a unique pathological disorder. Rev Environ Health. 2015;30(4):251-271.

43. Elberling J, Skov PS, Mosbech H, Holst H, Dirksen A, Johansen JD. Increased release of histamine in patients with respiratory symptoms Clin Exp Allergy. 2007;37(11):1676-1680.

44. Saito M, Kumano H, Yoshiuchi K, et al. Symptom profile of multiple chemical sensitivity in actual life. Psychosom Med. 2005;67(2):318-325.

45. Mizukoshi A, Kumagai K, Yamamoto N, et al. In-situ real-time monitoring of volatile organic compound exposure and heart rate variability for patients with multiple chemical sensitivity. Int J Environ Res Public Health. 2015;12(10):12446-12465.

46. Orriols R, Costa R, Cuberas G, Jacas C, Castell J, Sunyer J. Brain dysfunction in multiple chemical sensitivity. J Neurol Sci. 2009;287:72-78.

47. Gundersen H, Harris A, Bråtveit M, Moen BE. Odor related chronic somatic symptoms are associated with self-reported asthma and hay fever: the Hordaland Health Study. Iran J Allergy Asthma Immunol. 2015;14(1):19-27.

48. Bertschler J, Butler JR, Lawlis GF, Rea WJ, Johnson AR. Psychological components of environmental illness: factor analysis of changes during treatment. Clin Ecol. 1985;III(2):85-94.

49. Heuser G, Wojdani A, Heuser S. Diagnostic markers of multiple chemical sensitivity. Multiple Chemical Sensitivities: Addendum to Biologic Markers in Immunotoxicology. Washington, DC: National Research Council; 1992:117-138.

50. Fox RA, Sampalli T. Adaptation to low levels of chemical exposure in individuals with multiple chemical sensitivity in a controlled indoor environment. Indoor Built Environ. 2015;24(5):713-721.

51. Cui X, Lu X, Hisada A, Fujiwara Y, Katoh T. The correlation between mental health and multiple chemical sensitivity: a survey study in Japanese workers. Environ Health Prev Med. 2015;20(2):123-129.

52. Dantoft TM, Andersson L, Nordin S, Skovbjerg S. Chemical intolerance. Curr Rheumatol Rev. 2015;11(2):167-184.

53. Dumit J. Illnesses you have to fight to get: facts as forces in uncertain, emergent illnesses. Soc Sci Med. 2006;62(3):577-590.

54. Fox MH, Kim K. Understanding emerging disabilities. Disabil Soc. 2004;19(4):323-337.
55. Gibson PR. Of the world but not in it: barriers to community access and education for persons with environmental sensitivities. Health Care Women Int. 2010;31(1):3-16.

56. Gibson PR, Lindberg A. Work accommodation for people with multiple chemical sensitivity. Disabil Soc. 2007;22(7):717-732.

57. Gibson PR. Chemical and electromagnetic exposures as disability barriers: environmental sensitivity. Disabil Soc. 2009;24(2):187-199.

58. Gibson PR, Vogel VM. Sickness related dysfunction in persons with self-reported multiple chemical sensitivity at four levels of severity. J Clin Nurs. 2009;18(1):72-81.

59. Geller JL, Harris M. Women of the Asylum: Voices from Behind the Walls, 1840-1945. New York: Doubleday; 1994.

60. Laurence L, Weinhouse B. Outrageous Practices: The Alarming Truth about How Medicine Mistreats Women. New York: Fawcett Columbine; 1994.

61. Showalter E. The Female Malady: Women, Madness, and English Culture, 1830-1980. New York: Penguin; 1985.

62. Hamilton S, Rothbart M, Dawes RM. Sex bias, diagnosis and DSM-III. Sex Roles. 1985;15:268-274.

63. Loring M, Powell B. Gender, race and DSM-III: a study of the objectivity of psychiatric diagnostic behavior. J Health Soc Behav. 1988;29(1):1-22.

64. Doiron N. People with environmental sensitivities: Life, identity, and services, Doctoral Thesis in Social Work, University of Toronto, 2007.

65. Gibson PR, Suwal S, Sledd LG. Services requested and received by consumers with chemical sensitivities at the centers for independent living [Online Journal]. Disabil Stud Q. 2009;29(2):10.

66. Diener E, Emmons RA, Larsen RJ, Griffin S. The satisfaction with life scale. J Pers Assess. 1985;49:71-75.

67. Diener E. Subjective well being. Psychol Bull. 1984;95:542-575.

68. Arrindell WA, Meevwesen L, Huyse FJ. The satisfaction with life scale (SWLS): psychometric properties in a non-psychiatric medical outpatients sample. Pers Indiv Differ. 1991;12(2):117-123.

69. Egeli NA, Crooks VA, Matheson D, Ursa M, Marchant E. Patients' views: improving care for people with fibromyalgia. J Clin Nurs. 2008; 17:362-369.

70. Gibson PR. Multiple Chemical Sensitivity: A Survival Guide. 2nd ed. Churchvillle, VA: Earthrive Books; 2006.

71. Klonoff E, Landrine H. Preventing Misdiagnosis of Women. Thousand Oaks, CA: Sage; 1996.

72. Gibson PR, Elms ANM, Ruding LA. Perceived treatment efficacy for conventional and alternative therapies reported by persons with multiple chemical sensitivity. Environ Health Perspect. 2003;111(12):1498-1504.

73. Gibson PR, White MA, Rice VM. Life satisfaction in persons with invisible disabilities: chemical sensitivity/chemical injury. Poster Delivered at the 21st National Conference, Association for Women in Psychology, March 6-9. Pittsburgh, PA: 1997.

74. Lewis VG, Borders LD. Life satisfaction of single middle aged professional women. J Couns Dev. 1995;74(1):94-99.

75. Bernard AL, Prince A, Edsall P. Quality of life issues for fibromyalgia patients. Arthritis Care Res. 2000;13(1):42-50.

76. Lehman AM, Lehman DR, Hemphill KJ, Mandel DR, Cooper LM. Illness experience, depression, and anxiety in chronic fatigue syndrome. J Psychosom Res. 2002;52(6):461-465.

77. Koch L, Vierstra C, Penix K. A qualitative investigation of the psychosocial impact of multiple chemical sensitivity. J Appl Rehabil Couns. 2006;37(3):33-40.

78. Gibson PR, Leaf B, Komisarcik V. Unmet medical care needs in persons with multiple chemical sensitivity: a grounded theory of contested illness. J Nurs Educ Pract. 2016;6(5):75-83. 


\section{Publish your work in this journal}

The Journal of Multidisciplinary Healthcare is an international, peerreviewed open-access journal that aims to represent and publish research in healthcare areas delivered by practitioners of different disciplines. This includes studies and reviews conducted by multidisciplinary teams as well as research which evaluates the results or conduct of such teams or

healthcare processes in general. The journal covers a wide range of areas and welcomes submissions from practitioners at all levels, from all over the world. The manuscript management system is completely online and includes a very quick and fair peer-review system. Visit http://www.dovepress.com/testimonials.php to read real quotes from published authors.

Submit your manuscript here: http://www.dovepress.com/journal-of-multidisciplinary-healthcare-journal 